Asian Clinical Symposium

Regional Differences in Atherosclerotic Risk Factors and Cardiovascular Outcomes in Asian Population

\title{
Complication of Acute Myocardial Infarction in Relation with Major Risk Factors
}

Djoko Soemantri

Department of Cardiology Faculty of Medicine, Airlangga University/Dr. Soetomo General Hospital Surabaya, Indonesia

J Atheroscler Thromb, 2014; 21:S30.

This topic was presented at the Asian Clinical Symposium which was held during the 44th Annual Scientific Meeting of the Japan Atherosclerosis Society on July 20, 2012 in Fukuoka, Japan. 